\title{
HIGH TEMPERATURE-SHORT TIME (HTST) PROCESSING OF SUSPENSIONS CONTAINING BACTERIAL SPORES
}

\section{INTRODUCTION}

HTST STERILIZATION of foods, fermentation media and other biological suspensions often requires what appear to be irrationally high $\mathrm{F}$ values (Pfeifer and Vojnovich, 1952). This follows from the fact that these $F$ values are usually based upon the time-temperature heating pattern of the fluid in which the particles are suspended rather than upon the timetempcrature profiles attained inside the particles. Wollen (1970) states that acceptable HTST processes can be developed for viscous foods containing large pieces of meat if the meat is partially precooked. It is intuitively evident that pieces of whole or ground meat in fluids will heat more slowly than the solutions in which they are suspended, and secondly that the larger such particles are, a longer exposure time will be required for lethal heat to penetrate to their centers. For example when gravy stews are processed at $240^{\circ} \mathrm{F}$ in tin cans, the slow heat penetration to the center of particles is relatively unimportant. This follows because with the long heating times involved, the contents of the can are at the temperature of the heating menstruum $\left(240^{\circ} \mathrm{F}\right)$ for so long a time that the $\theta_{\mathrm{T}}$. values (effective time values) contributed during the "come-up" and cooling periods are small. However, as temperatures of the heating medium are increased and the necessary heating times are shortened in order to attain the improved quality and increased vitamin retention that HTST processing provides (Busta, 1967; Pfeifer and Vojnovich, 1952; Townsend et al., 1938), the time required for heat penetration to the coldest spots in particles becomes the controlling factor of the thermal process. It is a characteristic of the very high temperatures of $280^{\circ} \mathrm{F}$ and above that are now used for HTST processing (Busta, 1967), that the unsteady state, transient temperatures, prevailing during heating and cooling portions of the processing cycle represent most if not all of the sterilization interval insofar as particles are concerned. Indeed, with very short time-very high temperature processing, the centers of large parti-

\footnotetext{
Present address: E \& J Gallo Winery, Modesto, CA 95353
}

cles likely never attain a steady state temperature or even reach any where near the temperature of the surrounding heating fluid. While this situation is recognized both practically and intuitively, few attempts have been made to study it (Pfeifer and Vojnovich, 1952; Townsend et al., 1938).

The present paper is designed to demonstrate quantitatively that HTST processing conditions for suspensions of particles in water solutions must be based upon the $F$ values delivered at the coldest spot inside the particles, not upon that developed in the surrounding medium. In order to demonstrate quantitatively the above objective of this paper, a protection ratio (PR) was defined and computed; the PR is intended to be used only for this demonstration.

\section{MATERIALS \& METHODS}

\section{Preparation of spore suspensions}

Bacillus subtilis 5230 was obtained from the Food Science Department at Michigan State University. The culture was characterized according to accepted methods (Cowan and Steel,

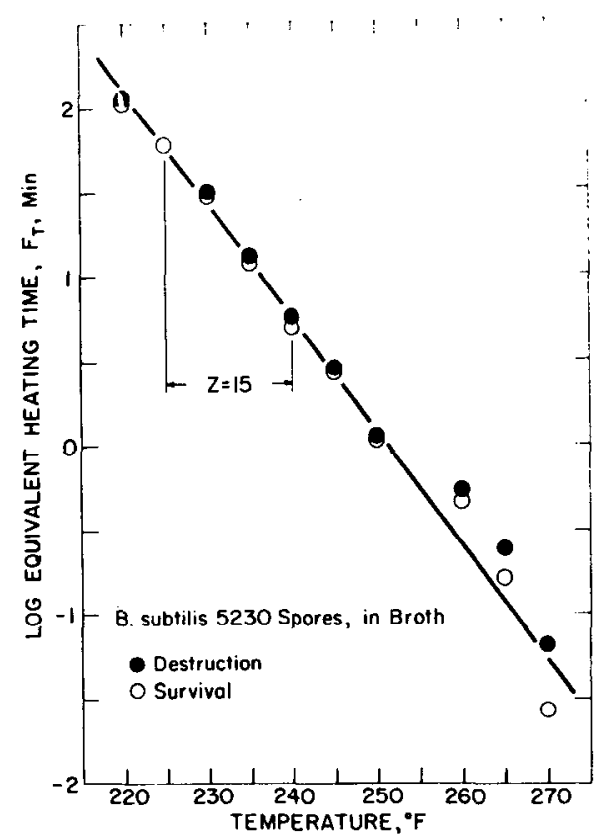

Figure 1-Thermal death time curve for $B$. subtilis 5230 spores in TPT's containing broth, heated in ethylene glycol.
1966; Smith et al., 1952). All spores used came from one suspension. They were harvested from surface cultures grown for $96 \mathrm{hr}$ at $37^{\circ} \mathrm{C}$ on nutrient agar (Difco) containing $1 \mu \mathrm{g} / \mathrm{ml} \mathrm{Mn}$ ion. The spores were washed four times by centrifugation in sterile distilled water and stored at $4^{\circ} \mathrm{C}$ in distilled water (Jacobs et al., 1965). After a $15 \mathrm{~min}$ heat shock in boiling water, initial spore counts were established using nutrient agar (Difco) as the plating medium.

\section{Preparation and processing of TPT's}

Thermal processing studies were conducted in thermal processing tubes (TPT's) similar to the TDT tubes described by other workers (Bigelow and Estry, 1920; Sognefest and Benja$\mathrm{min}, 1944)$. These TPT's measure $12 \mathrm{~mm}$ in diam, $75 \mathrm{~mm}$ long and were made of borosilicate glass. Multiple tubes were used at each exposure time (Esty and Williams, 1924). The TPT's were charged with broth prepared from nutrient broth (Difco) containing $0.5 \%$ dextrose and $0.5 \%$ soluble starch and adjusted to $\mathrm{pH} 6.60$ (Busta, 1967). 2 cc of broth were aseptically pipetted into half of the sterile TPT's; the remainder received $1.4 \mathrm{cc}$ of broth plus a broth saturated particle having a volume of $0.6 \mathrm{cc}$. These particles were rolls prepared from strips of chromatography paper (Whatman no. 1) measuring $254 \times 12.7 \mathrm{~mm}$. The individ-

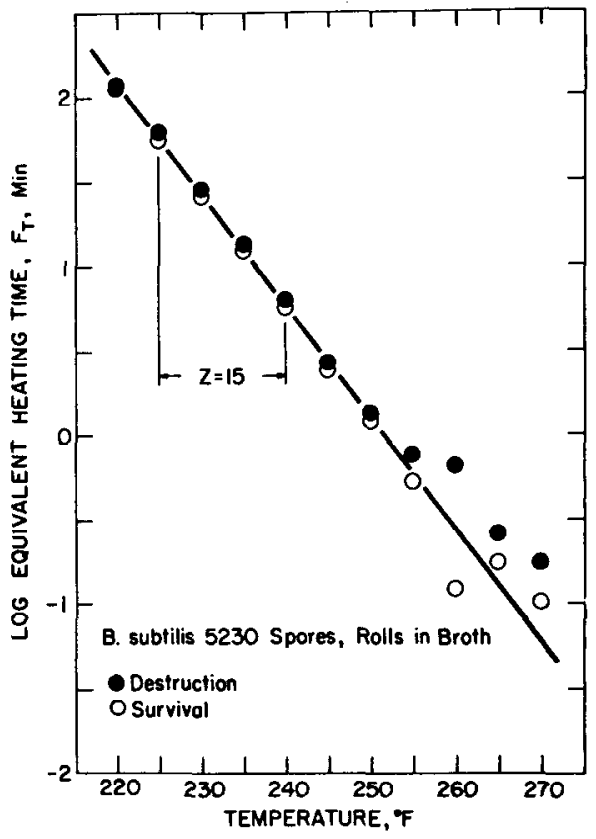

Figure 2-Thermal death time curve for B. subtilis 5230 spores within rolls placed in TPT's containing broth, heated in ethylene glycol. 
ual strips were rolled into tight cylinders 12.7 $\mathrm{mm}$ long by $7.64 \pm 0.16 \mathrm{~mm}$ in diam. They were autoclaved three times in distilled water at $15 \mathrm{psig}$ for $1 \mathrm{hr}$ at each autoclaving, vacuum dried while hot, and then immersed in broth and sterilized at $15 \mathrm{psig}$ for $40 \mathrm{~min}$. The sterile, broth saturated rolls were stored overnight at $4^{\circ} \mathrm{C}$ in the sterile broth and then aseptically inoculated through one end into their geometric centers with $0.05 \pm 0.0010 \mathrm{ml}$ of $B$. subtilis 5230 spore suspension containing $17,200,000$ spores per mil of distilled water. The spores were not heat shocked previous to inoculation because heat processing would accomplish this.

Thermal processing was conducted in an ethylene glycol heating bath controlled within $\pm 0.10^{\circ} \mathrm{F}$. It was large enough so that no measurable temperature drop occurred when 30 TPT's were immersed. The temperature was set with a thermometer that had been calibrated against a copper-constantan thermocouple.

Table 1-Results of multiple-tube exposure series at $260^{\circ} \mathrm{F}$ for establishing the thermal death time for B. subtilis $\mathbf{5 2 3 0}$ spores contained in broth or in a roll and placed within TPT's ${ }^{\mathrm{a}}$

\begin{tabular}{cccc}
\hline $\begin{array}{c}\text { Actual } \\
\text { processing } \\
\text { time (min) }\end{array}$ & $\begin{array}{c}\text { Inoculated } \\
\text { broth }\end{array}$ & $\begin{array}{c}\text { Actual } \\
\text { processing } \\
\text { time (min) }\end{array}$ & $\begin{array}{c}\text { Inoculated } \\
\text { rolls }\end{array}$ \\
\hline 1.20 & $5 / 5$ & 1.80 & $5 / 5$ \\
1.30 & $1 / 5$ & 1.95 & $5 / 5$ \\
1.40 & $0 / 5$ & 2.10 & $3 / 5$ \\
1.50 & $1 / 5$ & 2.25 & $2 / 5$ \\
1.60 & $0 / 5$ & 2.40 & $2 / 5$ \\
1.70 & $0 / 5$ & 2.60 & $0 / 5$ \\
\hline
\end{tabular}

a Initial concentration was 860,000 spores per tube or per roll. Results are given as number of tubes with growth per number of tubes exposed.

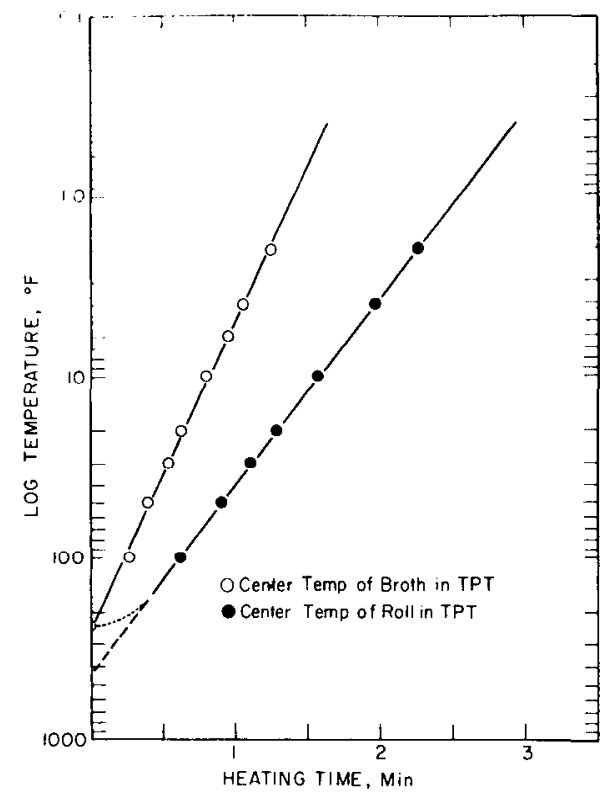

Figure 3-Semilog plot of heating curves showing the difference between bath temperature and the center temperature of broth or rolls in TPT's versus heating time. Bath temperature, $270^{\circ} \mathrm{F}$.
The TPT's were flame-sealed $37 \mathrm{~mm}$ above the level of the liquid. A piece of cotton string $2 \mathrm{~mm}$ thick was placed between the tube and a 22-gauge copper wire that was tightly wrapped twice around the tube about $10 \mathrm{~mm}$ above the liquid level. Five tubes were selected at random and bundled together with a lead weight to submerge the lubes in the bath. Bundles were so arranged as to maintain acceptable separation of the tubes. Six bundles were suspended on a steel rod which was used to manually immerse the tubes into the hot glycol. Timing began at the instant that the bundles of TPT's contacted the glycol. One bundle of 5 TPT's was removed from the rod at each exposure time and immediately plunged into ice-water. After thermal processing, the unopened tubes were incubated at $37^{\circ} \mathrm{C}$ for 4 days and examined. They were then reincubated another 10 days for confirmation.

Growth was indicated by the development of turbidity, but if questionable it was confirmed by testing for the presence of acid using brom-cresol-purple. The results obtained were evaluated for survival or destruction of microorganisms (Bigelow, 1921; Bigelow and Esty, 1920; Townsend et al., 1938). Survival times were those at which some of the tubes in a bundle showed growth; destruction times were those at which all tubes in a bundle showed no growth. Skips were considered positive.

\section{Processing calculations}

Rather than experimentally determining the time-temperature profiles for all eleven processing temperatures studied, the profiles were experimentally observed at $240,250,260$ and $270^{\circ} \mathrm{F}$. Then a computer program was written to predict these profiles using the data at $270^{\circ} \mathrm{F}$ and the plotting method of Olson and Jackson (1942). Since results from the computer program agreed with the experimental data at 240 , 250,260 and $270^{\circ} \mathrm{F}$, computer results were routinely used for all the time-temperature profiles.

Lethal heating values produced by the rapidly changing temperatures at the coldest spots in the TPT's were computed by a modification (Kempe, 1955) of the improved general method (Schultz and Olson, 1940). Equivalent processing times were expressed in minutes at each processing temperature. These were designated $\theta_{\mathbf{E}}$ at $250^{\circ} \mathrm{F}$ or $\theta_{\mathbf{T}}$ at the other temperatures, $\mathbf{T}$. The minimum $\theta_{\mathbf{E}}$ and $\theta_{\mathbf{T}}$ needed to sterilize

Table 2-Survival and destruction time for B. subtilis $\mathbf{5 2 3 0}$ spores contained in broth or in a roll placed within TPT's. Each TPT contained a total medium volume of $2.0 \mathrm{cc}^{\mathrm{a}}$

\begin{tabular}{|c|c|c|c|c|c|}
\hline \multirow{2}{*}{$\begin{array}{c}\text { Temperature } \\
\left(^{\circ} \mathrm{F}\right)\end{array}$} & & \multicolumn{2}{|c|}{ Inoculated broth } & \multicolumn{2}{|c|}{ Inoculated rolls } \\
\hline & & A & $\theta_{\mathbf{T}}$ & A & $\theta_{\mathbf{T}}$ \\
\hline \multicolumn{6}{|l|}{220} \\
\hline & Survival & 110.0 & $10 \mathbb{2}^{2} j$ & 115.0 & 113.1 \\
\hline & Destruction & 115.0 & 113.8 & 120.0 & 118.1 \\
\hline \multicolumn{6}{|l|}{225} \\
\hline & Survival & 60.5 & 59.49 & 57.2 & 55.3 \\
\hline & Destruction & - & - & 60.5 & 58.6 \\
\hline \multicolumn{6}{|l|}{230} \\
\hline & Survival & 30.0 & 28.95 & 27.5 & 25.56 \\
\hline & Destruction & 32.5 & 31.45 & 30.0 & 28.06 \\
\hline \multicolumn{6}{|l|}{235} \\
\hline & Survival & 13.0 & 11.95 & 14.0 & 12.05 \\
\hline & Destruction & 14.0 & 12.95 & 15.0 & 13.05 \\
\hline \multicolumn{6}{|l|}{240} \\
\hline & Survival & 6.0 & 4.94 & 7.50 & 5.54 \\
\hline & Destruction & 6.75 & 5.69 & 8.25 & 6.29 \\
\hline \multicolumn{6}{|l|}{245} \\
\hline & Survival & 3.70 & 2.64 & 4.40 & 2.43 \\
\hline & Destruction & 4.00 & 2.94 & 4.60 & 2.63 \\
\hline \multicolumn{6}{|l|}{250} \\
\hline & Survival & 2.10 & 1.03 & 3.15 & 1.18 \\
\hline & Destruction & 2.20 & 1.13 & 3.30 & 1.33 \\
\hline \multicolumn{6}{|l|}{255} \\
\hline & Survival & 1.80 & 0.73 & 2.42 & 0.53 \\
\hline & Destruction & 1.92 & 0.85 & 2.66 & 0.72 \\
\hline \multicolumn{6}{|l|}{260} \\
\hline & Survival & 1.50 & 0.45 & 2.40 & 0.486 \\
\hline & Destruction & 1.60 & 0.54 & 2.60 & 0.654 \\
\hline \multicolumn{6}{|l|}{265} \\
\hline & Survival & 1.14 & 0.160 & 1.95 & 0.175 \\
\hline & Destruction & 1.26 & 0.243 & 2.10 & 0.261 \\
\hline \multicolumn{6}{|l|}{270} \\
\hline & Survival & 0.84 & 0.027 & 1.80 & 0.102 \\
\hline & Destruction & 0.96 & 0.064 & 1.95 & 0.172 \\
\hline
\end{tabular}

aInitial concentration was 860,000 spores per tube. The actual processing time (A) and the equivalent processing time $\left(\theta_{T}\right)$, in minutes, are given. 
the system at $250^{\circ} \mathrm{F}$ and at temperature $\mathrm{T}$, were designated as $\mathrm{F}$ and $\mathbf{F}_{\mathbf{T}}$ respectively.

The $z$ value required for determining the equivalent processing times was calculated by a computer with a Fortran Program (Powell, 1970). The computer results were checked against a graphical calculation. Either method was repeated until the assumed and computed $\mathrm{z}$ values agreed within $0.1^{\circ} \mathrm{F}$. A disparity in slope and shape of the resulting curves occurred when the assumed and computed $\mathrm{z}$ values differed. TDT curves were plotted for each system from the linear equations determined hy the regression analyses of the experimental data (Fig. 1 and 2).

Table 1 shows the results from a multiplctube exposure series that was used to establish the thermal death time for B. subtilis 5230 spores at $260^{\circ} \mathrm{F}$. Although a skip occurred at $1.40 \mathrm{~min}$, the last survival time and the first destruction time were considered to be 1.50 and $1.60 \mathrm{~min}$ respectively. Table 2 summarizes the survival and destruction times obtained for each temperature evaluated.

An example of the method of calculation, using the data obtained at $260^{\circ} \mathrm{F}$, follows. An equivalent processing time for the coldest spot in any TPT was calculated once a $z$ value was known and a heat penetration curve was available. A plot of the temperature changes occurring in a spore suspension contained in the broth or in the filter-paper rolls in the TPT's versus the time of immersion is shown in Figures 3 and 4 . Next, Figure 5 , the factor curve, was plotted for data at $260^{\circ} \mathrm{F}$. Since $260^{\circ} \mathrm{F}$ was taken as the reference temperature in Figure 5, the spore killing time factor, $K_{T}$, becomes the lethal rate when $z=15$ and $F_{260}=1$; an equivalent $F_{260}$ value for $1 \mathrm{~min}$ holding time at any temperature between 215 and $275^{\circ} \mathrm{F}$ can then be read from this curve. For example, $1 \mathrm{~min}$ of exposure at $230^{\circ} \mathrm{F}$ is 0.01 as lethal as $1 \mathrm{~min}$ of exposure at $260^{\circ} \mathrm{F}$. The equivalent processing time was then calculated for $260^{\circ} \mathrm{F}$ as shown in Table 3 based on Figures 3, 4 and 5 .

\section{RESULTS \& DISCUSSION}

THE PROCEDURES adopted for the study reported in this paper assume that a particle in a fluid, like a piece of meat in a gravy stew, or a dumpling in chicken soup, heats and cools as if it were a very small can of solid material immersed in a heat transfer fluid. If a time-temperature profile is available, then the effective heating time, $\theta_{\mathbf{T}}$, at any temperature can be computed by several methods, of which Kempe's modification of the "general method" is one (Kempe, 1955). With a "general method," it is only necessary to know the time-temperature profiles at the coldest spot in the system when these values are to be computed. It is unnecessary to have information about the rate of heat transfer, the thermal conductivity of various components, or other thermal properties of the system when the timetemperature profiles are known from experimental data. For this reason, the time-temperature profiles at the coldest spot in the broth in the TPT's were first measured with a thermocouple and a timer, as were similar profiles at the center of the paper rolls which were submerged in nutrient broth and were resting on the bottom of the TPT's. If such profiles were to be computed rather than measured, then an entirely different situation would exist.

The heat penetration curves shown in Figures 3 and 4 , obtained for the TPT's

containing broth or broth with roll, have the familiar shape described in the literature (Olson and Jackson, 1942; Stumbo, $1965)$. The $z$ value for the $B$. subtilis 5230 spores in TPT's containing broth or broth with rolls (Fig. 1 and 2) was $15 \mathrm{~min}$ and was similar to the values obtained by

Table 3-Graphical computation of the minimum equivalent heating time, $\theta_{\mathrm{T}}$, producing ste. rility at $260^{\circ} \mathrm{F}$ at the coldest spot in a $12 \times 75 \mathrm{~mm}$ thermal processing tube (TPT) containing $2 \mathrm{cc}$ of medium $^{a}$

\begin{tabular}{|c|c|c|c|c|c|}
\hline $\begin{array}{c}\text { Time } \\
\text { interval } \\
\text { (min) }\end{array}$ & $\begin{array}{l}\text { Avg temp } \\
\text { during time } \\
\text { interval } \\
\text { (Fig. 1) } \\
\text { (F) }\end{array}$ & $\begin{array}{c}\text { Length } \\
\text { of } \\
\text { time } \\
\text { (min) }\end{array}$ & $\begin{array}{c}\text { Factor } \\
\left(K_{T}\right)\end{array}$ & $\begin{array}{c}\text { Increments } \\
\text { of equiva- } \\
\text { lent time, } \\
\theta_{\mathrm{T}} \text {, at } \\
260^{\circ} \mathrm{F} \\
\text { (min) }\end{array}$ & $\begin{array}{c}\text { Cumulative } \theta_{\mathbf{T}} \\
\text { increments at } \\
260^{\circ} \mathrm{F} \\
\left(\Sigma \theta_{\mathrm{T}}\right) \\
(\mathrm{min})\end{array}$ \\
\hline
\end{tabular}

TPT's containing $2 \mathrm{cc}$ of inoculated broth

$\begin{array}{llllll}0.00-0.30 & 106.0 & 0.3 & 0.000000 & 0.0000000 & 0.0000000 \\ 0.30-0.40 & 195.0 & 0.1 & 0.000047 & 0.0000047 & 0.0000047 \\ 0.40-0.50 & 215.5 & 0.1 & 0.00108 & 0.000108 & 0.0001127 \\ 0.50-0.60 & 230.0 & 0.1 & 0.010 & 0.0010 & 0.0011127 \\ 0.60-0.70 & 239.5 & 0.1 & 0.043 & 0.0043 & 0.0054127 \\ 0.70-0.80 & 246.0 & 0.1 & 0.118 & 0.0118 & 0.0172127 \\ 0.80-0.90 & 251.7 & 0.1 & 0.275 & 0.0275 & 0.0447127 \\ 0.90-1.00 & 253.7 & 0.1 & 0.370 & 0.0370 & 0.0817127 \\ 1.00-1.10 & 255.8 & 0.1 & 0.510 & 0.0510 & 0.1327127 \\ 1.10-1.20 & 257.1 & 0.1 & 0.642 & 0.0642 & 0.1969127 \\ 1.20-1.28 \mathrm{~b} & 258.4 & 0.08 & 0.780 & 0.0624 & 0.2593127 \\ 1.28-1.29 & 257.9 & 0.01 & 0.700 & 0.0070 & 0.2663127 \\ 1.29-1.31 & 252.4 & 0.02 & 0.300 & 0.0060 & 0.2723127 \\ 1.31-1.33 & 240.4 & 0.02 & 0.050 & 0.0010 & 0.2733127 \\ 1.33-1.35 & 221.4 & 0.02 & 0.0028 & 0.000056 & 0.2733687 \\ 1.35-1.36 & 206.4 & 0.01 & 0.00027 & 0.0000027 & 0.2733714\end{array}$

Total thermal process: $1.36 \mathrm{~min}$

Total equivalent heating time: $\theta_{\mathbf{T}}=\mathrm{F}_{\mathbf{T}}=0.27 \mathrm{~min}$

TPT's containing $1.4 \mathrm{cc}$ of broth plus an inoculated, broth saturated, filter paper roll of $0.6 \mathrm{cc}$ volume

$\begin{array}{llllll}0.00-0.80 & 113.0 & 0.8 & 0.00000 & 0.000000 & 0.000000 \\ 0.80-0.90 & 202.0 & 0.1 & 0.00014 & 0.000014 & 0.000014 \\ 0.90-1.00 & 214.0 & 0.1 & 0.00087 & 0.000087 & 0.000101 \\ 1.00-1.10 & 223.5 & 0.1 & 0.00372 & 0.000372 & 0.000473 \\ 1.10-1.20 & 231.3 & 0.1 & 0.0122 & 0.00122 & 0.001693 \\ 1.20-1.30 & 237.5 & 0.1 & 0.032 & 0.0032 & 0.004893 \\ 1.30-1.40 & 242.2 & 0.1 & 0.065 & 0.0065 & 0.011393 \\ 1.40-1.50 & 246.0 & 0.1 & 0.118 & 0.0118 & 0.023193 \\ 1.50-1.60 & 249.0 & 0.1 & 0.185 & 0.0185 & 0.041693 \\ 1.60-1.70 & 251.3 & 0.1 & 0.262 & 0.0262 & 0.067893 \\ 1.70-1.80 & 253.1 & 0.1 & 0.348 & 0.0348 & 0.102693 \\ 1.80-1.90 & 254.6 & 0.1 & 0.432 & 0.0432 & 0.145893 \\ 1.90-2.00 & 255.7 & 0.1 & 0.510 & 0.0510 & 0.196893 \\ 2.00-2.10 & 256.6 & 0.1 & 0.584 & 0.0584 & 0.255293 \\ 2.10-2.13 \mathrm{~b} & 257.4 & 0.03 & 0.670 & 0.0201 & 0.275393 \\ 2.13-2.15 & 257.0 & 0.02 & 0.630 & 0.0126 & 0.287993 \\ 2.15-2.19 & 254.5 & 0.04 & 0.420 & 0.0168 & 0.304793 \\ 2.19-2.23 & 249.0 & 0.04 & 0.180 & 0.00720 & 0.311993 \\ 2.23-2.33 & 234.0 & 0.10 & 0.190 & 0.00190 & 0.313893 \\ 2.33-2.39 & 219.0 & 0.06 & 0.0190 & 0.00019 & 0.314083\end{array}$

Total thermal process: $2.39 \mathrm{~min}$

Total equivalent heating time: $\theta_{\mathbf{T}}=\mathrm{F}_{\mathbf{T}}=0.31 \mathrm{~min}$

aThe medium was inoculated with $0.05 \mathrm{ml}$ distilled water containing 860,000 Bacillus subtilis 5230 spores having a $z$ value of 15 . TPT's were submerged in ethylene glycol at $260^{\circ} \mathrm{F}$. Equivalent time $=($ Length of time $) \times\left(\right.$ Factor,$\left.K_{T}\right)$.

bplunged into ice water 


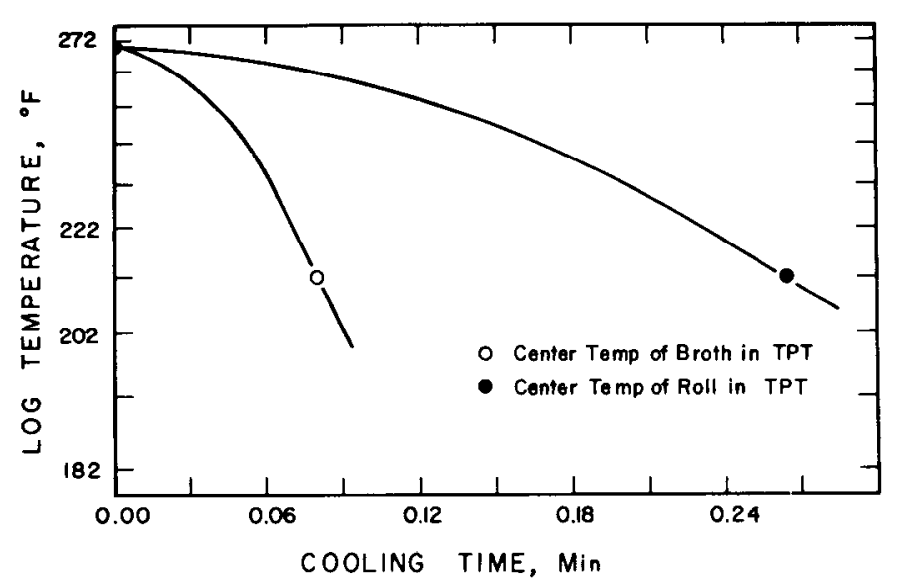

Figure 4-Semilog plot of cooling curves, showing temperature at center of broth or rolls in TPT's versus cooling time. Bath temperature, $270^{\circ} \mathrm{F}$.

others (Jacobs et al., 1965; Townsend et al., 1938). The data and computation methods can be tested by comparing the $\mathrm{F}_{\mathrm{T}}$ values for the $B$. sublilis 5230 spores in broth alone and in broth tubes containing rolls (Table 4 ). The $F_{T}$ values should be identical at a given temperature.

A technique is proposed that permits computing the heat insulating effect of particles on the time required to sterilize a system, when the particles are present in a liquid and a HTST process is applied. The heat insulating effect can be quantitated as a protection ratio (PR) which is computed by dividing the equivalent heating time, $\left(\mathrm{F}_{\mathrm{T}}\right)$, required to sterilize the broth in which a particle is suspended, by the equivalent processing time, $\left(\theta_{\mathrm{T}}\right)$, produced at the coldest spot within the particle which is in the broth at the instant that the $F_{T}$ is achieved. The protection ratio is defined as:

$$
P R=\frac{F_{T} \text { in broth }}{\theta_{T} \text { in the particle }}
$$

Protection ratios were established for each processing temperature evaluated in this study (Table 5). At temperatures from $220-230^{\circ} \mathrm{F}$ the protection ratio is approximately 1 ; from $235-250^{\circ} \mathrm{F}$, a small increase occurs as the temperature rises. Beginning at about $255^{\circ} \mathrm{F}$ the PR increases geometrically as a function of the processing temperature. At $270^{\circ} \mathrm{F}$, the equivalent processing time in the roll would need to be increased 855 -fold to effect sterilization inside the filter-paper rolls.

It may seem inconsistent to evaluate heat processing effects at $260^{\circ} \mathrm{F}$, for example, when the temperature inside particles in suspensions never reaches that temperature, as is evident in Table 3 . This however is the existing situation for industrial HTST sterilization procedures.
The same situation exists in hospitals where surgical gowns, bedding, etc. may be autoclaved at $250^{\circ} \mathrm{F}$ (Underwood, 1934). Here, air pockets in the gowns may prevent the temperature from reaching $250^{\circ} \mathrm{F}$ even after many minutes in the autoclave; yet the sterilization procedure would be reported to have been carried out at $250^{\circ} \mathrm{F}$.

For the purpose of discussion, let us consider the HTST system presented in Table 3 in the following context. The thermal processing temperature would be $260^{\circ} \mathrm{F}$. Assume that the broth containing $B$. subtilis 5230 spores could be instantaneously heated to $260^{\circ} \mathrm{F}$, held there for $0.27 \mathrm{~min}$, and instantaneously cooled to a sublethal temperature; the broth would be sterile. However, in order to sterilize the broth in a TPT, that is, for it to receive an effective processing time of

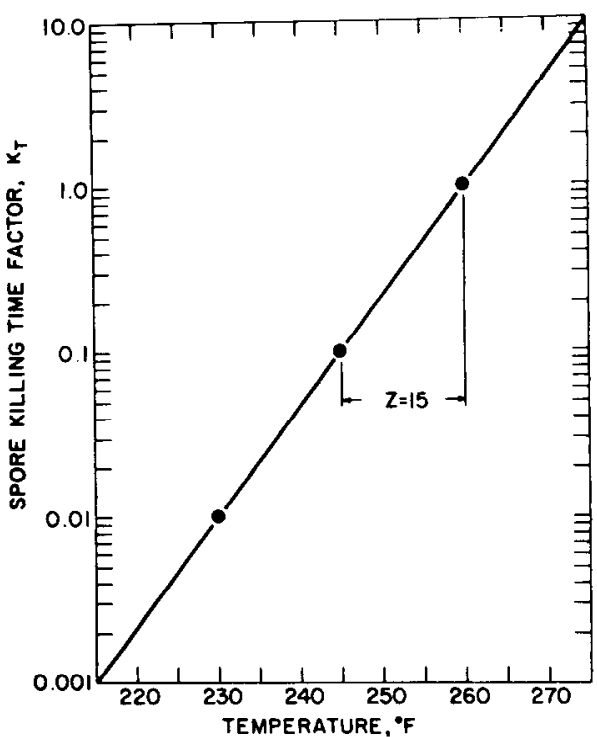

Figure 5-Factor curve relating the lethal effect of $1 \mathrm{~min}$ of exposure at $260^{\circ} \mathrm{F}$ to $1 \mathrm{~min}$ of exposure at another temperature. $11 \mathrm{~min}$ of exposure at $230^{\circ} \mathrm{F}$ is 0.01 as lethal as $1 \mathrm{~min}$ of exposure at $260^{\circ} \mathrm{F}$.)

$0.27 \mathrm{~min}$, it would need a thermal process of $1.36 \mathrm{~min}$. Likewise, the broth at the center of the paper rolls in TPT's would receive a $\theta_{\mathrm{T}}$ of $0.27 \mathrm{~min}$ only after a thermal process of $2.39 \mathrm{~min}$. Thus, for a $0.27 \mathrm{~min}$ process, the broth that was instantaneously heated became sterile, whereas the broth inside a TPT would scarcely have reached $100^{\circ} \mathrm{F}$, and a spore within a paper roll wouldn't have even been warmed! Such a situation may exist if a gravy or a soup were instantaneously heated to $260^{\circ} \mathrm{F}$, held there for $0.27 \mathrm{~min}$, and then instantaneously cooled to a

Table 4-Equivalent heating time, $F_{\mathrm{T}}$, required to kill 860,000 B. subtilis $\mathbf{5 2 3 0}$ spores in broth and in filter paper rolls contained in sealed $12 \times 75 \mathrm{~mm}$ culture tubes at various processing temperatures, $T$; determined by regression analyses of experimental data. Development of values for $260^{\circ} \mathrm{F}$ shown in Table 3

\begin{tabular}{|c|c|c|c|c|}
\hline \multirow[b]{2}{*}{$\begin{array}{c}\text { Processing } \\
\text { temp } \\
\left({ }^{\circ} \mathrm{F}\right)\end{array}$} & \multicolumn{2}{|c|}{ Inoculated broth } & \multicolumn{2}{|c|}{ Broth with inoculated rolls } \\
\hline & $\begin{array}{c}\text { Actual heating } \\
\text { time } \\
\text { (min) }\end{array}$ & $\begin{array}{c}\text { Equivalent } \\
\text { time, } F_{T} \\
(\min )\end{array}$ & $\begin{array}{c}\text { Actual } \\
\text { heating time } \\
(\mathrm{min})\end{array}$ & $\begin{array}{c}\text { Equivalent } \\
\text { time, } F_{T} \\
(\min )\end{array}$ \\
\hline 220 & 126.90 & 125.70 & 127.43 & 125.60 \\
\hline 225 & 59.15 & 58.15 & 60.85 & 58.75 \\
\hline 230 & 27.93 & 26.90 & 29.40 & 27.49 \\
\hline 235 & 13.49 & 12.44 & 14.79 & 12.87 \\
\hline 240 & 6.81 & 5.76 & 7.97 & 6.03 \\
\hline 245 & 3.72 & 2.67 & 4.78 & 2.84 \\
\hline 250 & 2.30 & 1.24 & 3.28 & 1.33 \\
\hline 255 & 1.63 & 0.58 & 2.54 & 0.62 \\
\hline 260 & 1.28 & 0.27 & 2.13 & 0.31 \\
\hline 265 & 1.08 & 0.13 & 1.87 & 0.134 \\
\hline 270 & 0.94 & 0.060 & 1.68 & 0.063 \\
\hline
\end{tabular}


Table 5-Protection ratio: the relationship between the computer calculated equivalent processing time, $F_{\mathbf{T}}$, required to produce sterility in the broth, and the calculated equivalent time, $\theta_{\mathrm{T}}$, developed at the center of the filter-paper roll, at the instant that sterility occurred in the broth

\begin{tabular}{cccc}
\hline $\begin{array}{c}\text { Temp } \\
\left({ }^{\circ} \mathrm{F}\right)\end{array}$ & $\begin{array}{c}\mathrm{F}_{\mathrm{T}} \text { broth } \\
(\mathrm{min})\end{array}$ & $\begin{array}{c}\theta_{\mathrm{T}} \text { roll } \\
(\mathrm{min})\end{array}$ & $\begin{array}{c}\text { Protection } \\
\text { ratio }\end{array}$ \\
\hline 220 & 125.693 & 125.065 & 1.01 \\
225 & 58.145 & 57.244 & 1.02 \\
230 & 26.896 & 26.016 & 1.04 \\
235 & 12.444 & 11.559 & 1.08 \\
240 & 5.7601 & 4.8713 & 1.18 \\
245 & 2.6683 & 1.7794 & 1.50 \\
250 & 1.2413 & 0.44245 & 2.81 \\
255 & 0.5773 & 0.06159 & 9.37 \\
260 & 0.2734 & 0.0061406 & 44.5 \\
265 & 0.1262 & 0.00063697 & 198.0 \\
270 & 0.05962 & 0.00006977 & 855.0 \\
\hline
\end{tabular}

sublethal temperature. Unfortunately, the temperature within a meat ball in the gravy or a dumpling in the soup would have scarcely been altered by the thermal process. Consequently, spores that may be present at their centers would not be destroyed.

It is interesting to compare the effective processing times after a 0.27 min exposure to $260^{\circ} \mathrm{F}$ for the TPT's with broth only and for TPT's with broth and rolls. They are $7.0 \times 10^{-8} \mathrm{~min}$ and $1.3 \times 10^{-16} \mathrm{~min}$ respectively. Their corresponding protection ratios would be $3.7 \times 10^{6}$ and $2.0 \times 10^{15}$ respectively.

This dramatically illustrates the fundamental issue stated earlier in this paper, namely, that during HTST processing procedures, particles suspended in fluids receive less lethal heating than the surrounding fluid. Unfortunately this concept is rarely considered when calculating industrial processing schedules. It is our opinion that these observations simply confirm quantitatively what should be obvious for HTST processing procedures, namely:

1. HTST processing schedules for suspensions must be based upon thermal processing conditions existing inside particles, not upon the thermal conditions in the suspending menstruum.

2. Particles in the heating medium may never reach the temperature of the heating medium

3. Thermal steady state may not be reached inside particles. Indeed, transient heating and cooling regimes may be the common condition inside particles during HTST processing.
4. HTST processing schedules should be separately evaluated for each food or fermentation medium containing particles. This is necessary because thermal properties of both the suspending fluid and of the particles not only vary individually but they are interrelated from a heat transfer standpoint.

This situation provides the basis for some interesting, exciting, and hopefully useful studies that could lead to relatively precise predictions of required HTST processing schedules for foods and fermentation media containing suspended solids.

\section{DEFINITIONS}

$\mathrm{F}=$ number of minutes required to produce sterility in a system having a uniform temperature of $250^{\circ} \mathrm{F}$; when the temperature varies with time, the $F$ is equivalent to the minimum $\theta \mathrm{E}$ required to produce sterility.

$F_{0}=$ the $F$ value when the $z$ value for the bacterium under consideration is $18^{\circ} \mathrm{F}$

$\mathrm{F}_{\mathbf{T}}=$ number of minutes required to produce sterility in a system having a uniform temperature, $\mathrm{T}$; when the temperature varies with time, the $F_{\mathbf{T}}$ is equivalent to the minimum $\theta_{\mathbf{T}}$ required to produce sterility.

$\theta_{\mathrm{E}}=$ equivalent time in minutes at $250^{\circ} \mathrm{F}$. The sum of the lethal effects calculated for small time intervals in a heat processing schedule using the appropriate $z$ value for the spores concerned.

$\theta \mathbf{T}=$ equivalent time in minutes at temperature, T. The sum of the lethal effects calculated for small time intervals in a heat processing schedule using the ap- propriate $\mathrm{z}$ value for the spores concerned. Note that $\theta \mathbf{T}=\theta_{\mathrm{E}}$ at $250^{\circ} \mathrm{F}$.

$\mathrm{K}_{\mathbf{T}}=$ conversion factor relating the lethal effect of $1 \mathrm{~min}$ at a reference temperature to the lethal effect of a time interval at another temperature, $T$, through the $z$ value, and with temperatures measured in degrees Fahrenheit.

\section{REFERENCES}

Bigelow, W.D. 1921. The logarithmic nature of thermal death time curves. J. Infect. Dis. 29: 528

Bigelow, W.D. and Esty, J.R. 1920. The thermal death point in relation to time of typical thermophilic organisms. J. Infect. Dis. cal therm 602

Busta, F.F. 1967. Thermal inactivation characteristics of bacterial spores at ultra high temperatures. Appl. Microbiol. 15: 640.

Cowan, S.T. and Steel, K.J. 1966. "Manual for the Identification of Medical Bacteria." Cambridge University Press, Cambridge.

Esty, J.R. and Williams, C.C. 1924. Heat resistance of bacterial spores. J. Infect. Dis. 34 518.

Jacobs, R.A., Nicholas, R.C. and Pflug, I.J. 1965. Heat resistance of Bacillus subtilis spores in atmospheres of different water content. Mich. Agr. Expt. Sta. Quart. Bull. 48 .

Kempe, L.L. 1955. Combined effects of heat and radiation in food sterilization. Appl. Microbiol. 3: 346

Olson, F.C. and Jackson, J.M. 1942. Heating curves, theory and practical application Ind. \& Eng. Chem. 34: 337.

Pfeifer, V.F. and Vojnovich, C. 1952. Continuous sterilization of media in biochemical processes. Ind. \& Eng. Chem. 44: 1940.

Powell, J.M. 1970. Development of Fortran program for calculating $\mathrm{z}$ values and equivalent heating times from thermal death time data. CM 890 Report. The University of Michigan, College of Engineering.

Schultz, O.T. and Olson, F.C. 1940. Thermal processing of canned foods in tin containers. 3. Recent improvements in the general method of thermal process calculation-A special coordinate paper and methods of special coordinate paper and methods of
converting initial and retort temperatures. converting initial and
Food Research 5: 399 .

Smith, N.R., Gordon, R.E, and Clark, F.E. 1952. Aeroble spore forming bacterla. U.S Dept. Agriculture, Agr. Monograph 16.

Sognefest, P. and Benjamin, H.A. 1944. Heating lag in thermal death-time cans and tubes. Food Research 9: 234

Stumbo, C.R. 1965. "Thermobacteriology in Food Processing." Academic Press, New York.

Townsend, C.T., Esty, J.R. and Baselt, F.C 1938. Heat resistance studies on spores of putrefactive anaerobes in relation to determination of safe processes for canned foods. Food Research 3: 323 .

Underwood, W.B. 1934. "A Textbook of Sterilization." The Lakeside Press, R.R. Donnelley \& Sons, Chicago.

Wollen, A.H. 1970. Advances in Europe. Food Engineering 42(11): 76 .

Ms received $7 / 3 / 72 ;$ revised $9 / 14 / 72 ;$ accepted 9/19/72.

Presented at the 71st Annual Meeting of the American Society for Microbiology in Minneapolis, May 2-7, 1971 .

This investigation was supported by research grants from The University of Michigan Institute of Science \& Technology and from General Mills Corp. The senior author was supported by U.S. Public Health Service Environmental Health Research Training Grant EC-00013.

We thank F.G. Bader, J.M. Powell and W. Nelson who contributed materially to portions of this study through their undergraduate and graduate research projects. 